\title{
Aequorin as a Useful Calcium-Sensing Reporter in Candida albicans
}

\author{
Dominique Sanglard
}

check for

updates

Citation: Sanglard, D. Aequorin as a Useful Calcium-Sensing Reporter in Candida albicans. J. Fungi 2021, 7, 319. https://doi.org/10.3390/jof7040319

Academic Editor: Juliana

Campos Junqueira

Received: 29 January 2021

Accepted: 19 April 2021

Published: 20 April 2021

Publisher's Note: MDPI stays neutral with regard to jurisdictional claims in published maps and institutional affiliations.

Copyright: (C) 2021 by the author. Licensee MDPI, Basel, Switzerland. This article is an open access article distributed under the terms and conditions of the Creative Commons Attribution (CC BY) license (https:/ / creativecommons.org/licenses/by/ $4.0 /)$.
Institute of Microbiology, University of Lausanne and University Hospital, CH-1011 Lausanne, Switzerland; Dominique.Sanglard@chuv.ch; Tel.: +41-21-3144083

\begin{abstract}
In Candida albicans, calcium ions $\left(\mathrm{Ca}^{2+}\right)$ regulate the activity of several signaling pathways, especially the calcineurin signaling pathway. $\mathrm{Ca}^{2+}$ homeostasis is also important for cell polarization, hyphal extension, and plays a role in contact sensing. It is therefore important to obtain accurate tools with which $\mathrm{Ca}^{2+}$ homeostasis can be addressed in this fungal pathogen. Aequorin from Aequorea victoria has been used in eukaryotic cells for detecting intracellular $\mathrm{Ca}^{2+}$. A codon-adapted aequorin $\mathrm{Ca}^{2+}$-sensing expression system was therefore designed for probing cytosolic $\mathrm{Ca}^{2+}$ flux in C. albicans. The availability of a novel water-soluble formulation of coelenterazine, which is required as a cofactor, made it possible to measure bioluminescence as a readout of intracellular $\mathrm{Ca}^{2+}$ levels in $C$. albicans. Alkaline stress resulted in an immediate influx of $\mathrm{Ca}^{2+}$ from the extracellular medium. This increase was exacerbated in a mutant lacking the vacuolar $\mathrm{Ca}^{2+}$ transporter $V C X 1$, thus confirming its role in $\mathrm{Ca}^{2+}$ homeostasis. Using mutants in components of a principal $\mathrm{Ca}^{2+}$ channel (MID1, CCH1), the alkaline-dependent $\mathrm{Ca}^{2+}$ spike was greatly reduced, thus highlighting the crucial role of this channel complex in $\mathrm{Ca}^{2+}$ uptake and homeostasis. Exposure to the antiarrhythmic drug amiodarone, known to perturb $\mathrm{Ca}^{2+}$ trafficking, resulted in increased cytoplasmic $\mathrm{Ca}^{2+}$ within seconds that was abrogated by the chelation of $\mathrm{Ca}^{2+}$ in the external medium. $\mathrm{Ca}^{2+}$ import was also dependent on the Cch1/Mid1 $\mathrm{Ca}^{2+}$ channel in amiodarone-exposed cells. In conclusion, the aequorin $\mathrm{Ca}^{2+}$ sensing reporter developed here is an adequate tool with which $\mathrm{Ca}^{2+}$ homeostasis can be investigated in C. albicans.
\end{abstract}

Keywords: Candida; aequorin; calcium homeostasis; alkaline stress; amiodarone

\section{Introduction}

Fungal pathogens need to adapt rapidly to the different environments encountered in their host and need signaling molecules for this purpose. Among them, calcium ions $\left(\mathrm{Ca}^{2+}\right)$ play an important role. Changes in $\mathrm{Ca}^{2+}$ intracellular concentration in fungi mediate the rapid activation of signaling pathways linked to diverse cellular processes [1]. $\mathrm{Ca}^{2+}$ intracellular concentration therefore needs to be strictly controlled. In fungi, the cytosolic calcium concentration, $\left[\mathrm{Ca}^{2+}\right]$, is generally maintained at the sub-micromolar level by a calcium homeostasis system [2]. $\mathrm{Ca}^{2+}$ channels located in the plasma membrane and/or internal compartments can open to cause a rapid increase in cytosolic $\left[\mathrm{Ca}^{2+}\right]$ in a stimulusdependent manner. This is usually followed by a return to normal cytosolic $\left[\mathrm{Ca}^{2+}\right]$ through efflux from the cell or by uptake into specific organelles that serve as internal stores (vacuoles, mitochondria, endoplasmic reticulum) [2]. Candida albicans is one of the major fungal pathogens affecting human health [3]. C. albicans uses $\left[\mathrm{Ca}^{2+}\right]$ flux in order to rapidly modulate responses important for morphogenesis [4,5]. For example, Brand et al. [4] described that contact sensing and subsequent hyphal development is strongly affected by extracellular calcium chelation. $\left[\mathrm{Ca}^{2+}\right]$ flux is also important for $C$. albicans to cope with different stresses, and in particular with antifungal-dependent stresses [6-8]. One of the major stress response pathways in C. albicans is the calcium-dependent calcineurin pathway [9]. Blocking this pathway by chemical or genetic interference leads to a loss of 
resistance to these stresses [10]. In C. albicans, the calcium-dependent calcineurin pathway is also associated with the maintenance of virulence and thus highlights the importance of $\left[\mathrm{Ca}^{2+}\right]$ flux control in the context of the host [7]. In this fungal pathogen, $\mathrm{Ca}^{2+}$ entry has been showed to be mediated at least by a channel complex composed of CCH1 and MID1 [11]. C. albicans harbors a putative $\mathrm{Ca}^{2+} / \mathrm{H}^{+}$exchanger, $\mathrm{Vcx} 1$, a Ca ${ }^{2+}$ pump, Pmc1 [12], and a Ca ${ }^{2+}$ channel, Yvc1, in the vacuolar membrane [13]. Interestingly, Yvc1 in C. albicans was shown to play a role in cell polarization and hyphal extension, which is critical for the maintenance of virulence in this pathogenic yeast species [14]. A Ca ${ }^{2+} / \mathrm{Mn}^{2+}$ pump, Pmr1, has been described in the Golgi membrane [15], which may collaborate to maintain cytosolic $\mathrm{Ca}^{2+}$ homeostasis. In Saccharomyces cerevisiae, its deletion increases cytosolic $\left[\mathrm{Ca}^{2+}\right][16]$.

One issue in the measurement of $\mathrm{Ca}^{2+}$ flux in fungi is the detection of intracellular $\left[\mathrm{Ca}^{2+}\right]$. Several indirect reporters of intracellular $\left[\mathrm{Ca}^{2+}\right]$ have been used, including fluorescent dyes and $\mathrm{Ca}^{2+}$-binding proteins that emit luminescence or are linked to the reconstitution of GFP [17]. Here, we report the use of a codon-adapted form of aequorin in C. albicans for the measurement of intracellular $\mathrm{Ca}^{2+}$. Aequorin is a $22 \mathrm{kDa}$ calciumactivated photoprotein isolated from the hydrozoan Aequorea victoria [18]. The aequorin photoprotein is composed of apoaequorin, coelenterazine and bound oxygen, and shows a high affinity for free $\mathrm{Ca}^{2+}$. On binding to $\mathrm{Ca}^{2+}$, aequorin is converted into apoaequorin, carbon dioxide and coelenteramide, and energy from this reaction is released as blue light. The amount of released luminescence is dependent upon the concentration of free $\mathrm{Ca}^{2+}$, and thus aequorin can be used to measure intracellular $\left[\mathrm{Ca}^{2+}\right]$ [19]. In this study, the use of a novel water-soluble coelenterazine formulation to reconstitute a functional light-emitting protein enabled light emission in whole $C$. albicans cells after exposure to various extracellular cues. This $\mathrm{Ca}^{2+}$-reporter system was used to probe $\mathrm{Ca}^{2+}$ flux in mutants lacking key $\mathrm{Ca}^{2+}$ exchangers/channels in this important fungal pathogen.

\section{Materials and Methods}

\subsection{Strains and Media}

Strains used in this study are listed in Table S1. Strains were grown in the following media (when grown on solid media, $2 \%$ agar (Difco) was added): complete medium yeast extract peptone dextrose (YEPD): 1\% Bacto peptone (Difco Laboratories, Basel, Switzerland), $0.5 \%$ Yeast extract (Difco) and 2\% glucose (Fluka, Buchs, Switzerland); YEPD supplemented with $200 \mu \mathrm{g} / \mathrm{mL}$ nourseothricin (Werner BioAgents, Jena, Germany); minimal medium yeast nitrogen base (YNB): YNB (Difco) and $2 \%$ glucose (Fluka); YNB supplemented with complete supplement mixture (CSM) (MP Biomedicals); YNB supplemented with CSM without uracil (-ura) (MP Biomedicals, Luzern, Switzerland); FOA agar: YNB supplemented with $50 \mathrm{mg} / \mathrm{mL}$ uridine and $0.34 \mathrm{mg} / \mathrm{mL}$ FOA (5-fluoroorotic acid). E. coli DH5a was used as a host for plasmid constructions and propagation. DH5a was grown in LB broth or LB-agar plates, supplemented with ampicillin $(0.1 \mathrm{mg} / \mathrm{mL})$ or chloramphenicol $(0.1 \mathrm{mg} / \mathrm{mL})$ as required.

\subsection{Aequorin Expression in C. albicans}

The aequorin gene in the yeast expression vector pEVP11 [20] was codon-optimized for expression for C. albicans. CTG codons in the aequorin ORF (codons 96 and 133) were first replaced by TTG codons in two rounds of fusion PCRs. A first fusion PCR used 2 fragments originating from PCR products obtained with primer pairs AOQ-5/AOQ-NHE and AOQ-3/AOQ-PST (Table S2) using pEVP11 as a template. A second fusion PCR used 2 fragments originating from $\mathrm{PCR}$ products obtained with primer pairs AOQ2-5/AOQ-NHE and AOQ2-3/AOQ-PST (Table S2), using the first fusion product as a template. The $C$. albicans aequorin expression plasmid was constructed as follows: First, the ACT1 promoter from pACT1-GFP [21] was cloned as a $1 \mathrm{~kb}$ XhoI-PstI fragment into the same sites of pGFP [21] to give pDS1208. The codon-optimized aequorin gene was amplified in the second fusion step as described. After digestion by PstI and NheI, it was cloned into the vector backbone of pDS1208 after digestion with the same restriction enzymes, to 
replace GFP to give plasmid pDS1209 (Figure S1), in which the expression of aequorin is driven by the ACT1 promoter. The URA3 marker in pDS1209 was replaced by the SAT1 dominant marker as a $1.8 \mathrm{~kb}$ NotI-SpeI fragment from pVT50 (Sanglard lab collection) in the NotI/XbaI-digested vector background to give pDS1885 (Figure S1). Both plasmids were digested with StuI for integration into the RPS1 locus of C. albicans [22].

\subsection{Luminescence Measurements}

C. albicans strains were grown overnight in $\mathrm{YNB}$ - ura liquid medium at $30^{\circ} \mathrm{C}$ under constant shaking. Cells were next diluted to a cell density of $2 \times 10^{7}$ cells $/ \mathrm{mL}$ in $10 \mathrm{~mL}$ $\mathrm{YNB}$ - ura and grown under the same condition for $2 \mathrm{~h}$. Water-soluble coelenterazine (catalog \#3032, Nanolight Technology, Pinetop, AZ, USA) was resuspended in $5 \mathrm{~mL}$ PBS (phosphate buffered saline: $137 \mathrm{mM} \mathrm{NaCl}, 2.7 \mathrm{mM} \mathrm{KCl}, 4.3 \mathrm{mM} \mathrm{Na} 2 \mathrm{HPO}_{4}, 1.47 \mathrm{mM}$ $\mathrm{KH}_{2} \mathrm{PO}_{4}$ ) and kept in the dark. An aliquot of $100 \mu \mathrm{L}$ of this suspension was added to the $10 \mathrm{~mL}$ culture, wrapped with aluminium paper, and incubated for a further $3 \mathrm{~h}$. The cells were next kept on ice, centrifuged, washed with cold $1 \%$ glucose water solution, and finally resuspended in 1-1.5 $\mathrm{mL} \mathrm{1 \%}$ glucose water solution with $5 \mathrm{mM} \mathrm{Na}$-acetate ( $\mathrm{pH}$ 5.0; GLAC medium) to a cell density of $2-4 \times 10^{8}$ cells $/ \mathrm{mL}$.

Luminescence was read in a FLUOstar Omega instrument (BMG Labtech, Champigny / Marne, France). Cells $(100 \mu \mathrm{L})$ were dispensed in a microtiter plate (OptiPlate-96 plate, PerkinElmer, Schwerzenbach, Switzerland). The instrument was kept at a temperature of $30^{\circ} \mathrm{C}$. Baseline luminescence was determined by shaking the plate for $3 \mathrm{~s}$ and reading the luminescence at intervals of $1.5 \mathrm{~s}$ for 10-20 s. This was followed by the injection of small volumes $(5-15 \mu \mathrm{L})$ of diverse reagents followed by $1 \mathrm{~s}$ of shaking. Luminescence was read for another 110-120 s with $1.5 \mathrm{~s}$ intervals. To quantify total luminescence emitted by each strain, SDS and $\mathrm{CaCl}_{2}$ were injected to final concentrations of $0.15 \%$ and $100 \mathrm{mM}$, respectively. This aimed to permeabilize cells in order to measure total possible emitted luminescence for each cell type investigated in this study. Total possible luminescence was calculated by area under the curve (AUC) and were always above AUCs calculated in each of the stress experiments. Alkaline stress was induced by the simultaneous injection of $15 \mu \mathrm{L} 0.25 \mathrm{M}$ Tris- $\mathrm{HCl}$ (pH 7.5) and $10 \mu \mathrm{L} 1 \mathrm{M} \mathrm{CaCl}_{2}$ to the cell suspension, which resulted in a $\mathrm{pH}$ shift from 5.0 to 7.5. Amiodarone hydrochloride (Sigma-Aldrich Chemie $\mathrm{GmbH}$, Buchs, Switzerland) was prepared from a frozen stock of $50 \mathrm{mM}$ DMSO by first diluting it to $25 \mathrm{mM}$ with EtOH with further dilution to $0.5 \mathrm{mM}$ in GLAC medium with $10 \% \mathrm{EtOH}$. An aliquot of $10 \mu \mathrm{L}$ of this suspension was injected onto cells (50 $\mu \mathrm{M}$ final concentration). Luminescence data were exported to GraphPad Prism software (Version 9.1.0, GraphPad Software, San Diego, CA, USA) for data quantification and representation.

\subsection{Mutant Construction}

The VCX1 deletion mutant was constructed using a URA-blaster method. VCX1 flanking regions (around 500-bp) were amplified by primer pairs VCX-Kpn/VCX-BgB and VCX-PstB/VCX-HinB (Table S2) and cloned sequentially into compatible sites of pMB7 [23] to obtain plasmid pDS1629. The plasmid was linearized with ApaI and SacI to liberate the deletion cassette that was used in C. albicans transformations. After deletion of the first $V C X 1$ allele and verification by PCR, the URA3 marker was recycled by 5-FOA resistance selection on FOA agar resulting in isolate DSY4026. A second round of deletion was carried out in this isolate with the same deletion cassette to obtain the homozygous VCX1 mutant DSY4034. The URA3 marker was removed through 5-FOA-resistance selection to obtain the Ura - isolate, DSY4058.

\subsection{Yeast Transformation}

Overnight precultures of C. albicans strains in YEPD were diluted 50-fold in $50 \mathrm{~mL}$ fresh medium and incubated at $30{ }^{\circ} \mathrm{C}$ to a cell density of $2 \times 10^{7}$ cells $/ \mathrm{mL}$. Cultures were washed twice in LiAc/TE (TE: $10 \mathrm{mM}$ Tris-HCl pH 7.5, 1 mM EDTA; 0.1 M LiAc pH 7.5) and resuspended in $200 \mu \mathrm{L}$ of $\mathrm{LiAc} / \mathrm{TE}$. Competent cells were stored at $4{ }^{\circ} \mathrm{C}$. Competent 
cells $(50 \mu \mathrm{L})$ were mixed with $5 \mu \mathrm{L}$ denatured salmon sperm DNA $(10 \mathrm{mg} / \mathrm{mL}), 5-10 \mu \mathrm{g}$ of plasmids of interest, and $300 \mu \mathrm{L}$ PEG (TE with $0.1 \mathrm{M} \mathrm{LiAC} \mathrm{pH} \mathrm{7.5,} \mathrm{40 \%} \mathrm{PEG} \mathrm{4000).}$ Cells were incubated for $30 \mathrm{~min}$ at $30{ }^{\circ} \mathrm{C}$ then $15 \mathrm{~min}$ at $42{ }^{\circ} \mathrm{C}$. Transformed cells were pelleted and washed in TE and plated onto selective media. Plates were incubated onto the corresponding selective medium for 2 days at $34{ }^{\circ} \mathrm{C}$.

\subsection{Immunodetection of Aequorin}

Proteins were extracted from log-phase cells using alkaline lysis according to [23]. Protein extracts were separated by SDS-10\% polyacrylamide gel electrophoresis (PAGE) and transferred by Western blotting to a nitrocellulose membrane. Pre-stained molecular weight proteins (Biorad) were used as standards. Congo red staining of blotted proteins was carried out as described elsewhere [24]. Immunodetection of aequorin was performed with an aequorin polyclonal antibody (Covalab SAS, Bron, France). Signals were revealed by chemoluminescence (ECL kit, GE Healthcare, Glatbrugg, Switzerland) with anti-rabbit HRP-labeled secondary antibody. Quantifications of Western blot signals were carried out by an ImageQuant LAS 4000 System (GE Healthcare Life Sciences, Glattbrugg, Switzerland). Chemoluminescence signals and Congo red staining intensities were quantified by the software ImageQuantTL (Version 1.3).

\subsection{Statistics}

Comparisons of RLU values between conditions were evaluated using GraphPad Prism (version 9.1.0, GraphPad Software, San Diego, CA, USA) by 2-way ANOVA tests comparing each time point for each condition with Fisher's least significant difference (LSD) method.

\section{Results}

\subsection{Establishing Aequorin Expression in C. albicans}

A codon-optimized version of aequorin for C. albicans was designed based on the aequorin gene available on the yeast expression vector pEVP11 [20]. The modified aequorin gene was placed under the control of the ACT1 promoter to obtain pDS1209 and pDS1885, plasmids containing the URA3 complementation marker or the dominant marker SAT1, respectively (Figure S1). The expression of aequorin was verified by immuno-blot analysis in wild-type and mutant $C$. albicans strains used in this study and few variations were observed (Figure 1A). The first attempts to obtain luminescence signals with whole $C$. albicans cells incubated with DMSO-soluble coelenterazine yielded results of variable quality, with low luminescence signals upon cell permeabilization (see below). This may have been caused by the poor penetration of coelenterazine in C. albicans; therefore, a novel water-soluble coelenterazine formulation [25] was used instead. After incubation with this formulation, high luminescence signals were obtained when cells were permeabilized with $0.15 \%$ SDS in the presence of $100 \mathrm{mM} \mathrm{CaCl}_{2}$ (Figure 1B).

\subsection{Probing of $\mathrm{Ca}^{2+}$ Flux by Alkaline Stress}

Using these experimental conditions, several $\mathrm{Ca}^{2+}$-mobilizing stimuli were tested with wild-type $C$. albicans cells and mutants lacking specific $\mathrm{Ca}^{2+}$ channels. It is known that shift to alkaline $\mathrm{pH}$ (alkaline stress) can result in increased cytoplasmic $\left[\mathrm{Ca}^{2+}\right]$ in $\mathrm{C}$. albicans [26]. When cells were exposed to a $\mathrm{Ca}^{2+}$ stress only $(100 \mathrm{mM} \mathrm{CaCl} 2)$, an increase in luminescence was observed in the wild-type, but at reduced levels (Figure 2A, solid blue line). When the $\mathrm{pH}$ of the medium was shifted by a pulse of a buffer from an acidic to an alkaline value ( $\mathrm{pH} 5-7.5$ ) together with $100 \mathrm{mM} \mathrm{CaCl}_{2}$, the aequorin-based $\mathrm{Ca}^{2+}$ capture system detected a significant increase in luminescence within seconds (Figure 2B). The $\mathrm{pH}$ shift produced a 20-fold increase in total luminescence in the wild-type as compared to $\mathrm{CaCl}_{2}$-only conditions. 
A

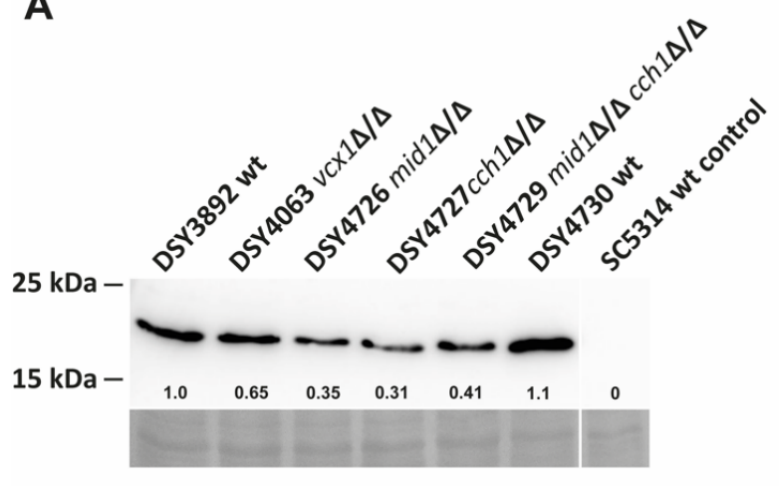

B

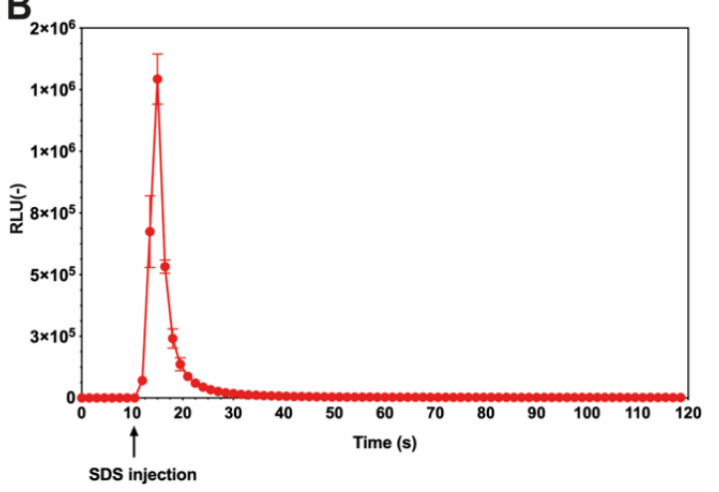

Figure 1. (A) Immuno-detection of aequorin in C. albicans by Western blot. Protein extracts were obtained as described in the Materials and Methods. Loading control images were obtained by Congo red staining of the nylon membrane after protein transfer. Pre-stained molecular weight standards are indicated at the left side. Designation of C. albicans isolates is indicated at the top. Aequorin signals (relative values) were quantified as described in the Materials and Methods using aequorin abundance signals of DSY3892 for reference and are indicated for each protein extract. Details of strain genotypes can be found in Table S1. wt: wild-type; wt control: untransformed wild-type. (B) Total luminescence emission of permeabilized C. albicans DSY3892 cells (Table S1). Cells were prepared as described in the Materials and Methods. SDS injection was performed after $10 \mathrm{~s}$ of pre-incubation in GLAC medium (arrow). Results were obtained from duplicate experiments and data were subtracted from the background in cells devoid of aequorin expression (CAF2-1). RLU: relative luminescence unit.

A

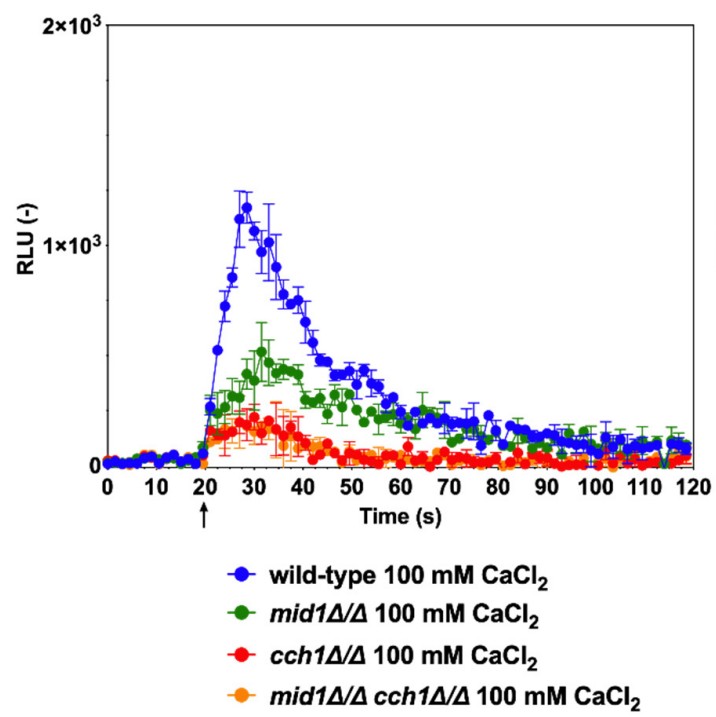

B

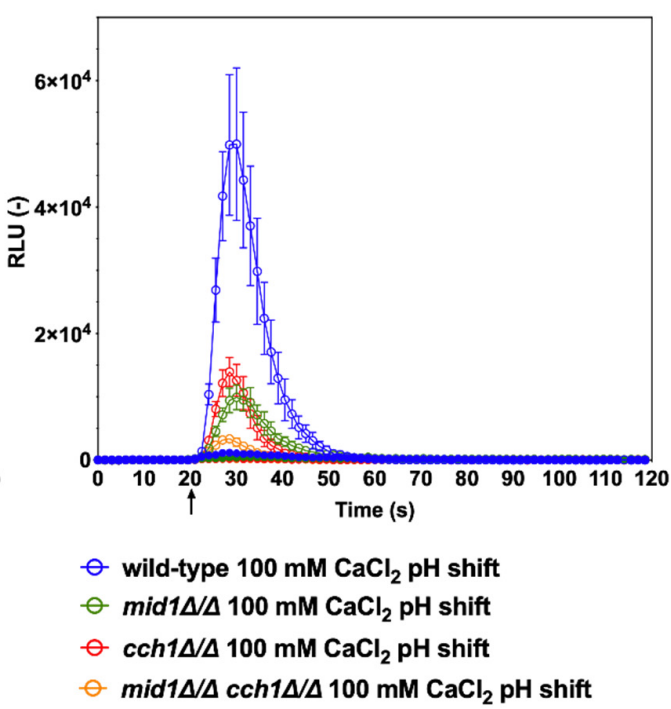

Figure 2. Alkaline stress induces a calcium spike in C. albicans. (A) Addition of $100 \mathrm{mM} \mathrm{CaCl}_{2}$ only. DSY3892 was used as the wild-type control strain. DSY4726, DSY4727 and DSY4729 (mid1 $\Delta / \Delta, \operatorname{cch} 1 \Delta / \Delta$ and mid1 $\Delta / \Delta \operatorname{cch} 1 \Delta / \Delta$ ) mutant cells were prepared as described in the Materials and Methods. Injection of $\mathrm{CaCl}_{2}(1 \mathrm{M})$ was performed after $20 \mathrm{~s}$ of pre-incubation in GLAC medium (arrow). Results were obtained from duplicate experiments and data were subtracted from background cells devoid of aequorin expression (CAF2-1). Comparisons of RLU values between the $\mathrm{CaCl}_{2}$-treated wild-type and mutants were significant $(p<0.001)$ after injections and after up to $50 \mathrm{~s}$ of experiment time had elapsed. Comparisons of RLU values between the $\mathrm{CaCl}_{2}$-treated mutants were not significant. (B) Addition of $100 \mathrm{mM} \mathrm{CaCl} 2$ and $\mathrm{pH}$ shift. Injection of $0.25 \mathrm{M}$ Tris- $\mathrm{HCl}(\mathrm{pH} 7.5)$ and $\mathrm{CaCl}_{2}(1 \mathrm{M})$ were performed after $20 \mathrm{~s}$ of pre-incubation in GLAC medium (arrow). Comparisons of RLU values between the $\mathrm{CaCl}_{2}$-treated cells and alkaline conditions were significant $(p<0.001)$ after injections and up to 30 to $50 \mathrm{~s}$ of experiment time had elapsed. Comparisons of RLU values between the wild-type and mutants under alkaline conditions were significant $(p<0.001)$ and up to $50 \mathrm{~s}$ of experiment time had elapsed. Comparisons of RLU values under alkaline conditions between mutants were significant $(p<0.001)$ up to $40 \mathrm{~s}$ of time had elapsed between the mid1 $\Delta / \Delta$ $\operatorname{cch} 1 \Delta / \Delta$ mutant and single mutants, although not significant between single mutants. Data in the $y$-axis are shown at a higher scale as compared to panel A. 
Mutants lacking the $\mathrm{CCH} 1$ and MID1 channels were tested in the same alkalineinduced conditions. The data showed that single $\operatorname{cch} 1 \Delta / \Delta$ and mid $1 \Delta / \Delta$ mutants exhibited significantly reduced $\mathrm{Ca}^{2+}$ accumulation as compared to wild-type, while the combination of both CCH1 and MID1 deletion resulted in a further reduction in $\mathrm{Ca}^{2+}$ accumulation (Figure 2B). The same trend was observed when only $\mathrm{Ca}^{2+}$ stress $(100 \mathrm{mM})$ was added; however, luminescence signals were also much reduced as compared to alkaline stress conditions (Figure 2A,B). Taken together, these data are consistent with the idea that alkaline stress can trigger a rapid $\mathrm{Ca}^{2+}$ accumulation in C. albicans, as previously published [26]. These data are also consistent with the requirement for the Cch1/Mid1 channel complex to mediate calcium entry into the cell cytoplasm in C. albicans [26,27]. Our data also suggest that additional $\mathrm{Ca}^{2+}$ uptake should be present in C. albicans because the absence of the Cch1/Mid1 channel complex could not completely abolish the activity of the aequorin reporter system (Figure 2B). One likely additional candidate in this process could be Factor Induced Gene 1 (Fig1), a component of the low-affinity calcium-uptake system (LACS), which is activated under specific conditions in C. albicans [28].

$\mathrm{Vcx} 1$ is a $\mathrm{H}^{+} / \mathrm{Ca}^{2+}$ exchanger located in the vacuolar membrane and uses the proton gradient across the vacuolar membrane (generated by a V-ATPase) to drive $\mathrm{Ca}^{2+}$ transport. Vcx1 enables excess cytoplasmic $\mathrm{Ca}^{2+}$ to be stored in the vacuole [29]. In the light of the previous results whereby alkaline stress induced a rise in cytoplasmic $\left[\mathrm{Ca}^{2+}\right]$, it was expected that, in the absence of $\mathrm{Vcx} 1$, this excess of $\mathrm{Ca}^{2+}$ would be further exaggerated. Indeed, the $v c x 1 \Delta / \Delta$ mutant emitted about a 2.5 -fold higher luminescence than the wildtype (Figure 3). Interestingly, the luminescence emission profile of the $v c x 1 \Delta / \Delta$ mutant exhibited a delay in the re-establishment of basal luminescence, indicating a perturbation in the kinetics of $\mathrm{Ca}^{2+}$ flux. These data are consistent with a reduced capacity of the $v c x 1 \Delta / \Delta$ mutant to store excess $\mathrm{Ca}^{2+}$ in the vacuole. Thus, the aequorin-based $\mathrm{Ca}^{2+}$ reporter assay enabled the verification of the role of $\mathrm{Vcx} 1$ in the maintenance of $\mathrm{Ca}^{2+}$ homeostasis in C. albicans.

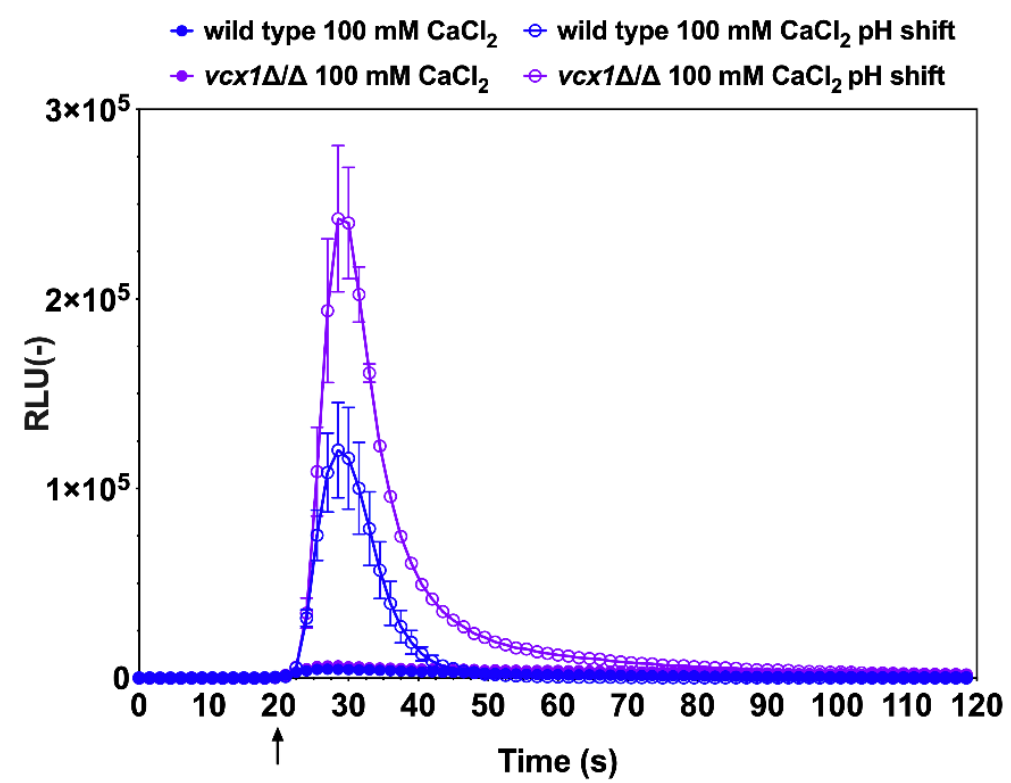

Figure 3. Relevance of the $\mathrm{H}^{+} / \mathrm{Ca}^{2+}$ exchanger, $\mathrm{Vcx} 1$, in $\mathrm{Ca}^{2+}$ homeostasis in C. albicans. Wild-type cells (DSY3892 and DSY4063) and the $v c x 1 \Delta / \Delta$ mutant were prepared as described in the Materials and Methods. Injections of $0.25 \mathrm{M}$ Tris- $\mathrm{HCl}(\mathrm{pH} 7.5)$ and $\mathrm{CaCl}_{2}(1 \mathrm{M})$ were performed after $20 \mathrm{~s}$ of pre-incubation in GLAC medium (arrow). Results were obtained from duplicate experiments and data were subtracted from background cells devoid of aequorin expression (CAF2-1). Comparisons of RLU values between the $\mathrm{CaCl}_{2}$-treated wild-type and $v c x 1 \Delta / \Delta$ mutants were not significant all time points, although they were significant $(p<0.001)$ in alkaline conditions after injections and up to $80 \mathrm{~s}$ of experiment time had elapsed. 


\subsection{Probing of $\mathrm{Ca}^{2+}$ Homeostasis by Amiodarone-Induced Stress}

Next, the effect of the antiarrhythmic drug amiodarone on $\mathrm{Ca}^{2+}$ homeostasis was tested with the wild-type $C$. albicans and a mutant lacking both $C C H 1$ and MID1. Amiodarone induces $\mathrm{Ca}^{2+}$ spikes in the budding yeast $S$. cerevisiae [30] and is also known to have fungicidal effects in C. albicans [31]. C. albicans cells were exposed to a low dose of amiodarone $(50 \mu \mathrm{M})$ and aequorin-dependent luminescence was detected even in the absence of external $\mathrm{CaCl}_{2}$ sources (Figure $4 \mathrm{~A}$, closed circles). Within seconds after amiodarone exposure, luminescence was emitted. This signal suggests either that trace $\mathrm{Ca}^{2+}$ was present in the testing medium (GLAC) and/or that internal $\mathrm{Ca}^{2+}$ stores were mobilized upon amiodarone stress. The addition of $1 \mathrm{mM} \mathrm{CaCl}_{2}$ in the GLAC medium recapitulated the emission of luminescence but, as expected, to much higher levels (Figure 4A, open circles). When the $\mathrm{Ca}^{2+}$ chelator BAPTA was added to wild-type cells, the luminescence emission was significantly reduced to low levels (Figure 4B, blue triangles), thus indicating that most luminescence signals in $\mathrm{CaCl}_{2}$-dependent conditions were due to the presence of $\mathrm{Ca}^{2+}$ from external sources. The residual luminescence signal during the chelation of $\mathrm{Ca}^{2+}$ by BAPTA was best observed after $60 \mathrm{~s}$ of experiment time had elapsed when compared to $\mathrm{CaCl}_{2}$ conditions (Figure $4 \mathrm{~B}$, blue triangles). This profile is likely to reflect the mobilization of $\mathrm{Ca}^{2+}$ from internal sources (for example vacuole, endoplasmic reticulum).
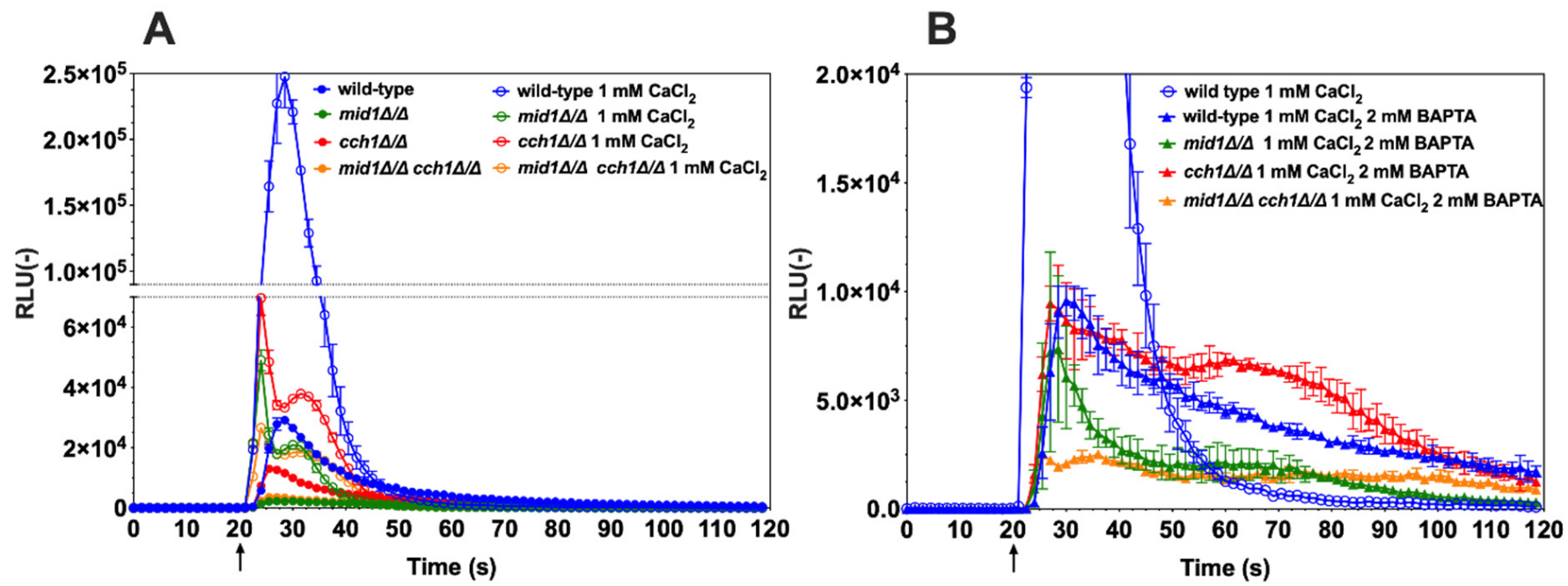

Figure 4. Amiodarone perturbs $\mathrm{Ca}^{2+}$ homeostasis in C. albicans. Wild-type (DSY4730, DSY4726, DSY4727 and DSY4729), $\operatorname{mid} 1 \Delta / \Delta, \operatorname{cch} 1 \Delta / \Delta$ and $\operatorname{mid} 1 \Delta / \Delta \operatorname{cch} 1 \Delta / \Delta$ cells were prepared as described in the Materials and Methods. Injection of amiodarone was performed after $20 \mathrm{~s}$ of pre-incubation in GLAC medium (arrow). (A) Effect of the addition of $\mathrm{CaCl}_{2}$ $(1 \mathrm{mM})$. Comparisons of RLU values between the absence and presence of $\mathrm{CaCl}_{2}$ in the amiodarone-treated wild-type and mutants were all significant $(p<0.001)$ after injections and up to $45 \mathrm{~s}$ of experiment time had elapsed. Comparisons of RLU values in the presence of $\mathrm{CaCl}_{2}$ and amiodarone between wild-type and mutants were all significant $(p<0.001)$. Comparisons of RLU values in the presence of $\mathrm{CaCl}_{2}$ and amiodarone between mutants were all significant $(p<0.001)$, with the exception between the mid1 $\Delta / \Delta$ and mid1 $\Delta / \Delta \operatorname{cch} 1 \Delta / \Delta$ mutants. (B) Effect of the addition of $\mathrm{CaCl}_{2}(1 \mathrm{mM})$ and BAPTA ( $2 \mathrm{mM})$, added before the start of the experiment. Results were obtained from duplicate experiments and data were subtracted from background cells devoid of aequorin expression (SC5314). A recapitulation of a CaCl 2 -only condition (panel A) is given for the wild-type comparison. Comparisons of $\mathrm{RLU}$ values between the presence of $\mathrm{CaCl}_{2}$ and BAPTA chelation in the amiodarone-treated wild-type and mutants were all significant $(p<0.001)$ after injections and up to $45 \mathrm{~s}$ of experiment time had elapsed. Comparisons of RLU values in the presence of $\mathrm{CaCl}_{2}$ and BAPTA chelation in amiodarone-treated conditions between wild-type and mutants were all significant $(p<0.001)$ with the exception of the comparison between wild-type and the $c c h 1 \Delta / \Delta$ mutant. Comparisons of RLU values in the presence of $\mathrm{CaCl}_{2}$ and BAPTA chelation in amiodarone-treated conditions between mutants were all significant $(p<0.001)$ but not between the mid1 $\Delta / \Delta$ $\operatorname{cch} 1 \Delta / \Delta$ and mid1 $\Delta / \Delta$ mutant after $35 \mathrm{~s}$ of experiment time laps. Data in the $y$-axis are shown at awer scale as compared to panel A. 
The same experiments were repeated with the mid $1 \Delta / \Delta, \operatorname{cch} 1 \Delta / \Delta$ and $\operatorname{cch} 1 \Delta / \Delta /$ mid $1 \Delta / \Delta$ mutants. First, when amiodarone was injected to the mutant cells in GLAC medium only, the luminescence recorded was significantly less than that for the wild-type (Figure 4A, closed circles). These data strongly suggest that most of the luminescence signal emitted by the wild-type when incubated under the same conditions was due to external $\mathrm{Ca}^{2+}$ sources. The addition of $1 \mathrm{mM} \mathrm{CaCl}_{2}$ to the mutants resulted first in a sharp increase in luminescence, which was next interrupted and followed by a second wave of luminescence (Figure 4A, open circles). The addition of BAPTA reduced these effects (Figure 4B, triangles). Of note is that the increase in luminescence was inhibited by a few seconds as compared to $\mathrm{CaCl}_{2}$-induced conditions, thus likely linked to the mobilization of internal $\mathrm{Ca}^{2+}$ sources as opposed to $\mathrm{CaCl}_{2}$-induced conditions. The most dramatic decrease in luminescence was obtained in the $\operatorname{cch} 1 \Delta / \Delta / \operatorname{mid} 1 \Delta / \Delta$ mutant (Figure $4 \mathrm{~B}$, orange triangles), highlighting the need to remove both units of this channel complex to maximally inhibit $\mathrm{Ca}^{2+}$ influx. Taken together, these results demonstrate the effect of amiodarone on $\mathrm{Ca}^{2+}$ flux in C. albicans, which acts by perturbing $\mathrm{Ca}^{2+}$ homeostasis in C. albicans, a step that could eventually lead to cell death.

\section{Discussion}

This study aimed first to establish aequorin as a robust system to probe $\mathrm{Ca}^{2+}$ flux in $\mathrm{C}$. albicans. Mechanisms that maintain $\mathrm{Ca}^{2+}$ homeostasis in this yeast species are important for transition to the hyphal growth stage of this fungus as well as for response to several stresses inflicted by both physical stimuli and chemical insult, such as antifungal agents.

As mentioned above, aequorin requires coelenterazine as a co-factor and it is only through the recent availability of a water-soluble coelenterazine formulation that sufficient and consistent luminescence signals could be obtained. The water-soluble coelenterazine formulation was also an advantage in vivo when used to detect luciferase-dependent reactions [25]. Other studies performed in filamentous fungi and budding yeast have used the standard form of hydrophobic coelenterazine that is only soluble in organic solvents [19,32]. The reason for the failure of hydrophobic coelenterazine for use in C. albicans remains unclear, however cell wall composition and other intrinsic properties of the C. albicans cell wall may be involved.

The luminescence signals that were obtained here can be converted and used to quantify the effective free $\left[\mathrm{Ca}^{2+}\right]$ in cells. Using a published formula [33], we estimated basal $\left[\mathrm{Ca}^{2+}\right.$ ] cytoplasmic concentrations within cells in the range of $0.02-0.05 \mu \mathrm{M}$. This is consistent with the concentration range obtained in other fungal cells [19,34]. Alkaline stress as reported here increased this concentration to about $0.75 \mu \mathrm{M}$ in wild-type cells, and thus is likely to reach toxic levels. As the data of this work show, these high free $\mathrm{Ca}^{2+}$ concentrations can, however, be rapidly decreased by the $\mathrm{C}$. albicans $\mathrm{Ca}^{2+}$ homoeostatic system. It is likely that these high transient $\mathrm{Ca}^{2+}$ spikes will in turn activate specific signaling pathways, among which the calcineurin signaling pathway is of significance because it is coupled with stress-response pathways, morphogenesis, and virulence [7,10,35-39].

The cell-based assay used here to report $\mathrm{Ca}^{2+}$ fluctuation in $\mathrm{C}$. albicans reports the behavior of a whole population. $\mathrm{Ca}^{2+}$ homeostasis is, however, highly compartmentalized in cells, and other tools need to be developed in order to obtain a more detailed overview of $\mathrm{Ca}^{2+}$ flux within individual cells. One approach is to develop an aequorin detection system that targets specific organelles [40]. A more powerful approach is to perform single cell imaging of $\mathrm{Ca}^{2+}$ flux. A FRET (Förster Resonance Energy Transfer)-based $\mathrm{Ca}^{2+}$ sensors of the Cameleon family has been successfully used in filamentous fungi to probe $\mathrm{Ca}^{2+}$ in individual cells [41]. A recent study reported the use of genetically encoded reporters called GCaMPs in the fungus Aspergillus fumigatus. GCaMP reporters are made of a circularly permuted (cp) GFP in between the calmodulin (CaM)-interacting region of chicken myosin light chain kinase (M13) at the N-terminus and a vertebrate CaM at the C-terminus. Binding of $\mathrm{Ca}^{2+}$ causes the M13 and CaM domains to interact and the resulting 
conformational change leads to an increase in cpGFP fluorescence [17]. Future studies should explore the feasibility of GCaMPs in C. albicans.

Only a few studies addressing C. albicans $\mathrm{Ca}^{2+}$ homeostasis are available for comparisons with the current study. It was shown by Wang et al. [26] that alkaline stress could result in a calcium influx from external sources that was dependent on the Mid1/Cch1 channel complex. Cytoplasmic $\left[\mathrm{Ca}^{2+}\right]$ was detected by flow cytometry with a fluorescent dye (fluo-3-AM-ester). The data obtained after alkaline stress resulted in a $120 \mathrm{~s}$ time-lapse increase in fluorescence without reversion to baseline fluorescence. This type of profile is essentially different from the current data, in which luminescence adopted a bell-shaped profile with a rapid increase (10 s) to maximal values (Figure 2). This type of response is much closer to a study in which $S$. cerevisiae was investigated for $\mathrm{Ca}^{2+}$ flux under alkaline stress [42]. As published by Wang et al. [26] for C. albicans, we confirm that alkaline stress response involves the Cch1/Mid1 channel complex. The same complex is also critical for $\mathrm{Ca}^{2+}$ homeostasis in many other fungal species [1]. The involvement of VCX1 in $\mathrm{Ca}^{2+}$ homeostasis was addressed by Jia et al. [43]. The authors found abnormal decreases in $\mathrm{Ca}^{2+}$ after alkaline stress, which was also observed here. VCX1-dependent $\mathrm{Ca}^{2+}$ spikes have been reported in S. cerevisiae [16]. Taken together, the data collected in this study are consistent with published studies, however our data reveal more detailed dynamics of $\mathrm{Ca}^{2+}$ homeostasis for C. albicans.

Amiodarone stress followed by $\mathrm{Ca}^{2+}$ response has not been yet investigated in C. albicans. This drug has a fungicidal effect in pathogens, and it can act synergistically with other antifungal agents $[31,44-46]$. Amiodarone triggers $\mathrm{Ca}^{2+}$ influx in S. cerevisiae, thus activating at least the $\mathrm{Ca}^{2+}$-dependent calcineurin pathway that is necessary to buffer this drug stress $[30,45,47,48]$. Interestingly, fluconazole was shown to exacerbate the amiodaronedependent increase in cytosolic $\left[\mathrm{Ca}^{2+}\right]$, thus revealing some mechanistic insight into the synergistic effect between the two drugs. Here, we show that amiodarone stress involves the $\mathrm{Ca}^{2+}$ complex containing Mid1 and $\mathrm{Cch} 1$ which allows $\mathrm{Ca}^{2+}$ uptake into the cytosol from the external environment. Interestingly, the absence of the Cch1/Mid1 channel did not completely eliminate $\mathrm{Ca}^{2+}$ uptake by C. albicans in the presence of amiodarone (Figure 4A), suggesting the role of additional components (Fig1) [28]. This rapid $\mathrm{Ca}^{2+}$ spike is then buffered by $\mathrm{Ca}^{2+}$ sequestration systems that likely involve vacuoles and/or the endoplasmic reticulum. More detailed analysis based on the use of specific $\mathrm{Ca}^{2+}$ homeostasis mutants could be used to answer this question. Using the strong calcium chelator BAPTA, we also indirectly showed here that amiodarone can mobilize internal $\mathrm{Ca}^{2+}$ sources, but the nature of these remains to be established. One of the likely candidates that may increase intracellular calcium from internal stores could be Ycv1, a vacuolar calcium channel important for intracellular $\mathrm{Ca}^{2+}$ homeostasis in C. albicans [14].

\section{Conclusions}

In conclusion, this work established that codon-optimized aequorin can be used in C. albicans as a convenient and reliable system with which to probe $\mathrm{Ca}^{2+}$ homeostasis. This system can be adapted for use in other pathogenic Candida spp. Future work can be undertaken to test not only the importance of specific $\mathrm{Ca}^{2+}$ transporters in response to diverse stresses or environmental conditions, but also to address the mechanisms that use $\mathrm{Ca}^{2+}$ flux to respond to the challenges presented by antifungal agents.

Supplementary Materials: The following are available online at https:/ /www.mdpi.com/article/10 .3390/jof7040319/s1, Figure S1: Plasmid maps of aequorin expression vectors, Table S1: Strains used in this study, Table S2: List of primers used in this study.

Funding: This research was funded a Swiss National Research Foundation grant 31003A_172958 to D.S.

Institutional Review Board Statement: Not applicable.

Informed Consent Statement: Not applicable. 
Data Availability Statement: The datasets generated during and/or analyzed during the current study are available from the corresponding author upon request.

Acknowledgments: The author thanks P.H. Masson for the gift of plasmid pEVP11 and F. Ischer for excellent technical assistance. Authors thanks J. Heitman (Duke University, USA) for providing CCH1 and MID1 mutants used here. The authors are thankful to A. Brand (University of Exeter) for critical reading.

Conflicts of Interest: The authors declare no conflict of interest.

\section{References}

1. Lange, M.; Peiter, E. Calcium Transport Proteins in Fungi: The Phylogenetic Diversity of Their Relevance for Growth, Virulence, and Stress Resistance. Front. Microbiol. 2020, 10, 3100. [CrossRef]

2. Tisi, R.; Rigamonti, M.; Groppi, S.; Belotti, F. Calcium homeostasis and signaling in fungi and their relevance forpathogenicity of yeasts and filamentous fungi. AIMS Mol. Sci. 2016, 3, 505-549. [CrossRef]

3. Cottier, F.; Hall, R.A. Face/Off: The Interchangeable Side of Candida Albicans. Front. Cell. Infect. Microbiol. 2020, 9, 471. [CrossRef]

4. Brand, A.; Lee, K.; Veses, V.; Gow, N.A.R. Calcium homeostasis is required for contact-dependent helical and sinusoidal tip growth in Candida albicanshyphae. Mol. Microbiol. 2009, 71, 1155-1164. [CrossRef] [PubMed]

5. Brand, A.; Gow, N.A.R. Mechanisms of hypha orientation of fungi. Curr. Opin. Microbiol. 2009, 12, 350-357. [CrossRef]

6. Karababa, M.; Valentino, E.; Pardini, G.; Coste, A.T.; Bille, J.; Sanglard, D. CRZ1, a target of the calcineurin pathway in Candida albicans. Mol. Microbiol. 2006, 59, 1429-1451. [CrossRef] [PubMed]

7. Sanglard, D.; Ischer, F.; Marchetti, O.; Entenza, J.; Bille, J. Calcineurin A of Candida albicans: Involvement in antifungal tolerance, cell morphogenesis and virulence. Mol. Microbiol. 2003, 48, 959-976. [CrossRef] [PubMed]

8. Cruz, M.; Goldstein, A.L.; Blankenship, J.R.; Del Poeta, M.; Davis, D.; Cardenas, M.E.; Perfect, J.R.; McCusker, J.H.; Heitman, J. Calcineurin is essential for survival during membrane stress in Candida albicans. EMBO J. 2002, 21, 546-559. [CrossRef] [PubMed]

9. Liu, S.; Hou, Y.; Liu, W.; Lu, C.; Wang, W.; Sun, S. Components of the Calcium-Calcineurin Signaling Pathway in Fungal Cells and Their Potential as Antifungal Targets. Eukaryot. Cell 2015, 14, 324-334. [CrossRef]

10. Chen, Y.-L.; Brand, A.; Morrison, E.L.; Silao, F.G.S.; Bigol, U.G.; Malbas, F.F.; Nett, J.E.; Andes, D.R.; Solis, N.V.; Filler, S.G.; et al. Calcineurin Controls Drug Tolerance, Hyphal Growth, and Virulence in Candida dubliniensis. Eukaryot. Cell 2011, 10, 803-819. [CrossRef]

11. Yu, Q.; Wang, H.; Cheng, X.; Xu, N.; Ding, X.; Xing, L.; Li, M. Roles of Cch1 and Mid1 in Morphogenesis, Oxidative Stress Response and Virulence in Candida albicans. Mycopathol. 2012, 174, 359-369. [CrossRef] [PubMed]

12. Jiang, L.; Alber, J.; Wang, J.; Du, W.; Yang, X.; Li, X.; Sanglard, D.; Geyer, J. The Candida albicans plasma membrane protein Rch1p, a member of the vertebrate SLC10 carrier family, is a novel regulator of cytosolic $\mathrm{Ca}^{2+}$ homoeostasis. Biochem. J. 2012, 444, 497-502. [CrossRef]

13. Yu, Q.; Wang, F.; Zhao, Q.; Chen, J.; Zhang, B.; Ding, X.; Wang, H.; Yang, B.; Lu, G.; Zhang, B.; et al. A novel role of the vacuolar calcium channel Yvc1 in stress response, morphogenesis and pathogenicity of Candida albicans. Int. J. Med Microbiol. 2014, 304, 339-350. [CrossRef]

14. Peng, L.; Yu, Q.; Wei, H.; Zhu, N.; Ren, T.; Liang, C.; Xu, J.; Tian, L.; Li, M. The TRP Ca ${ }^{2+}$ channel Yvc1 regulates hyphal reactive oxygen species gradient for maintenance of polarized growth in Candida albicans. Fungal Genet. Biol. 2019, 133, 103282. [CrossRef]

15. Bates, S.; MacCallum, D.M.; Bertram, G.; Munro, C.A.; Hughes, H.B.; Buurman, E.T.; Brown, A.J.; Odds, F.C.; Gow, N.A. Candida albicans Pmr1p, a Secretory Pathway P-type $\mathrm{Ca}^{2+} / \mathrm{Mn}^{2+}$-ATPase, Is Required for Glycosylation and Virulence. J. Biol. Chem. 2005, 280, 23408-23415. [CrossRef] [PubMed]

16. D’Hooge, P.; Coun, C.; Van Eyck, V.; Faes, L.; Ghillebert, R.; Mariën, L.; Winderickx, J.; Callewaert, G. Ca 2+ homeostasis in the budding yeast Saccharomyces cerevisiae: Impact of ER/Golgi Ca 2+ storage. Cell Calcium 2015, 58, 226-235. [CrossRef] [PubMed]

17. Muñoz, A.; Bertuzzi, M.; Seidel, C.; Thomson, D.; Bignell, E.M.; Read, N.D. Live-cell imaging of rapid calcium dynamics using fluorescent, genetically-encoded GCaMP probes with Aspergillus fumigatus. Fungal Genet. Biol. 2020, 103470, 103470. [CrossRef] [PubMed]

18. Knight, M.R.; Campbell, A.K.; Smith, S.M.; Trewavas, A.J. Transgenic plant aequorin reports the effects of touch and cold-shock and elicitors on cytoplasmic calcium. Nat. Cell Biol. 1991, 352, 524-526. [CrossRef]

19. Nelson, G.; Kozlova-Zwinderman, O.; Collis, A.J.; Knight, M.R.; Fincham, J.R.S.; Stanger, C.P.; Renwick, A.; Hessing, J.G.M.; Punt, P.J.; Hondel, C.A.M.J.J.V.D.; et al. Calcium measurement in living filamentous fungi expressing codon-optimized aequorin. Mol. Microbiol. 2004, 52, 1437-1450. [CrossRef]

20. Batiza, A.F.; Schulz, T.; Masson, P.H. Yeast Respond to Hypotonic Shock with a Calcium Pulse. J. Biol. Chem. 1996, 271, 23357-23362. [CrossRef] [PubMed]

21. Barelle, C.J.; Manson, C.L.; Maccallum, D.M.; Odds, F.C.; Gow, N.A.R.; Brown, A.J.P. GFP as a quantitative reporter of gene regulation in Candida albicans. Yeast 2004, 21, 333-340. [CrossRef] [PubMed] 
22. Murad, A.M.A.; Lee, P.R.; Broadbent, I.D.; Barelle, C.J.; Brown, A.J.P. CIp10, an efficient and convenient integrating vector forCandida albicans. Yeast 2000, 16, 325-327. [CrossRef]

23. Coste, A.T.; Karababa, M.; Ischer, F.; Bille, J.; Sanglard, D. TAC1, Transcriptional Activator of CDR Genes, Is a New Transcription Factor Involved in the Regulation of Candida albicans ABC Transporters CDR1 and CDR2. Eukaryot. Cell 2004, 3, 1639-1652. [CrossRef] [PubMed]

24. Wang, J.-L.; Zhao, L.; Li, M.-Q.; Chen, W.-G.; Xu, C.-J. A sensitive and reversible staining of proteins on blot membranes. Anal. Biochem. 2020, 592, 113579. [CrossRef]

25. Delarze, E.; Ischer, F.; Sanglard, D.; Coste, A.T. Adaptation of aGaussia princepsLuciferase reporter system in Candida albicansforin vivodetection in theGalleria mellonellainfection model. Virulence 2015, 6, 684-693. [CrossRef] [PubMed]

26. Wang, H.; Liang, Y.; Zhang, B.; Zheng, W.; Xing, L.; Li, M. Alkaline stress triggers an immediate calcium fluctuation in Candida albicans mediated by Rim101p and Crz1p transcription factors. FEMS Yeast Res. 2011, 11, 430-439. [CrossRef]

27. Reedy, J.L.; Filler, S.G.; Heitman, J. Elucidating the Candida albicans calcineurin signaling cascade controlling stress response and virulence. Fungal Genet. Biol. 2010, 47, 107-116. [CrossRef] [PubMed]

28. Yang, M.; Brand, A.; Srikantha, T.; Daniels, K.J.; Soll, D.R.; Gow, N.A.R. Fig1 Facilitates Calcium Influx and Localizes to Membranes Destined To Undergo Fusion during Mating in Candida albicans. Eukaryot. Cell 2011, 10, 435-444. [CrossRef]

29. Pittman, J.K. Vacuolar Ca ${ }^{2+}$ uptake. Cell Calcium 2011, 50, 139-146. [CrossRef]

30. Courchesne, W.E.; Ozturk, S. Amiodarone induces a caffeine-inhibited, MID1 -depedent rise in free cytoplasmic calcium in Saccharomyces cerevisiae. Mol. Microbiol. 2003, 47, 223-234. [CrossRef] [PubMed]

31. Gamarra, S.; Rocha, E.M.F.; Zhang, Y.-Q.; Park, S.; Rao, R.; Perlin, D.S. Mechanism of the Synergistic Effect of Amiodarone and Fluconazole in Candida albicans. Antimicrob. Agents Chemother. 2010, 54, 1753-1761. [CrossRef] [PubMed]

32. Tisi, R.; Martegani, E.; Brandão, R.L. Monitoring Yeast Intracellular $\mathrm{Ca}^{2+}$ Levels Using an In Vivo Bioluminescence Assay: Figure 1. Cold Spring Harb. Protoc. 2015, 2015, 210-213. [CrossRef] [PubMed]

33. Fricker, M.; Plieth, C.; Knight, H.; Blancaflor, E.; Knight, M.; White, N.; Gilroy, S. Fluorescence and Luminescence Techniques to Probe Ion Activities in Living Plant Cells. Fluoresc. Lumin. Probes Biol. Act. 1999, 569-596. [CrossRef]

34. Förster, C.; Kane, P.M. Cytosolic $\mathrm{Ca}^{2+}$ Homeostasis Is a Constitutive Function of the V-ATPase in Saccharomyces cerevisiae. J. Biol. Chem. 2000, 275, 38245-38253. [CrossRef] [PubMed]

35. Blankenship, J.R.; Wormley, F.L.; Boyce, M.K.; Schell, W.A.; Filler, S.G.; Perfect, J.R.; Heitman, J. Calcineurin Is Essential for Candida albicans Survival in Serum and Virulence. Eukaryot. Cell 2003, 2, 422-430. [CrossRef]

36. Bader, T.; Bodendorfer, B.; Schröppel, K.; Morschhäuser, J. Calcineurin Is Essential for Virulence in Candida albicans. Infect. Immun. 2003, 71, 5344-5354. [CrossRef]

37. Blankenship, J.R.; Heitman, J. Calcineurin Is Required for Candida albicans To Survive Calcium Stress in Serum. Infect. Immun. 2005, 73, 5767-5774. [CrossRef] [PubMed]

38. Cruz, M.; Fox, D.S.; Heitman, J. Calcineurin is required for hyphal elongation during mating and haploid fruiting in Cryptococcus neoformans. EMBO J. 2001, 20, 1020-1032. [CrossRef]

39. Kraus, P.R.; Heitman, J. Coping with stress: Calmodulin and calcineurin in model and pathogenic fungi. Biochem. Biophys. Res. Commun. 2003, 311, 1151-1157. [CrossRef]

40. Button, D.; Eidsath, A. Aequorin targeted to the endoplasmic reticulum reveals heterogeneity in luminal Ca++ concentration and reports agonist- or IP3-induced release of Ca++. Mol. Biol. Cell 1996, 7, 419-434. [CrossRef]

41. Kim, H.-S.; Czymmek, K.J.; Patel, A.; Modla, S.; Nohe, A.; Duncan, R.; Gilroy, S.; Kang, S. Expression of the Cameleon calcium biosensor in fungi reveals distinct $\mathrm{Ca}^{2+}$ signatures associated with polarized growth, development, and pathogenesis. Fungal Genet. Biol. 2012, 49, 589-601. [CrossRef] [PubMed]

42. Viladevall, L.; Serrano, R.; Ruiz, A.; Domenech, G.; Giraldo, J.; Barceló, A.; Ariño, J. Characterization of the Calcium-mediated Response to Alkaline Stress in Saccharomyces cerevisiae. J. Biol. Chem. 2004, 279, 43614-43624. [CrossRef] [PubMed]

43. Jia, C.; Zhang, K.; Yu, Q.; Zhang, B.; Xiao, C.; Dong, Y.; Chen, Y.; Zhang, B.; Xing, L.; Li, M. Tfp1 is required for ion homeostasis, fluconazole resistance and N-Acetylglucosamine utilization in Candida albicans. Biochim. Biophys. Acta (BBA) Bioenerg. 2015, 1853, 2731-2744. [CrossRef]

44. Butts, A.; DiDone, L.; Koselny, K.; Baxter, B.K.; Chabrier-Rosello, Y.; Wellington, M.; Krysan, D.J. A Repurposing Approach Identifies Off-Patent Drugs with Fungicidal Cryptococcal Activity, a Common Structural Chemotype, and Pharmacological Properties Relevant to the Treatment of Cryptococcosis. Eukaryot. Cell 2012, 12, 278-287. [CrossRef]

45. Muend, S.; Rao, R. Fungicidal activity of amiodarone is tightly coupled to calcium influx. FEMS Yeast Res. $2008,8,425-431$. [CrossRef] [PubMed]

46. Maresova, L.; Muend, S.; Zhang, Y.-Q.; Sychrova, H.; Rao, R. Membrane Hyperpolarization Drives Cation Influx and Fungicidal Activity of Amiodarone. J. Biol. Chem. 2009, 284, 2795-2802. [CrossRef]

47. Zhang, Y.-Q.; Rao, R. A spoke in the wheel: Calcium spikes disrupt yeast cell cycle. Cell Cycle 2008, 7, 870-873. [CrossRef]

48. Zhang, Y.-Q.; Gamarra, S.; Garcia-Effron, G.; Park, S.; Perlin, D.S.; Rao, R. Requirement for Ergosterol in V-ATPase Function Underlies Antifungal Activity of Azole Drugs. PLoS Pathog. 2010, 6, e1000939. [CrossRef] 